\title{
Higher Gensini Score of Coronary Arteries in Acute Inferior Myocardial Infarction with Precordial ST-Segment Depression
}

\author{
Kan Takayanagi, M.D., Hirokazu Yamaguchi, M.D., \\ Shigenori Morooka, M.D., and Yutaka Takabatake, M.D.
}

\section{SUMmary}

To investigate the significance of precordial ST-segment depression in acute inferior myocardial infarction, we compared the Gensini score of coronary artery stenosis between 2 groups of patients with and without precordial ST-segment depression. Group I consisted of 28 patients who showed ST-segment depression on admission $\left(\geq 1 \mathrm{~mm}\right.$ in $\left.\mathrm{V}_{2^{-}} \mathrm{V}_{6}\right)$ and Group II $(n=16)$ those without ST-segment depression $(<1 \mathrm{~mm})$. The Gensini score of the coronary arteries ( $56 \pm 29$ vs. $28 \pm 18 ; \mathrm{p}<0.001)$, the partial score of the infarction-related artery $(29 \pm 16$ vs. $17 \pm 11 ; \mathrm{p}<0.01)$ and of the infarction-nonrelated artery $(27 \pm 24$ vs. $11 \pm 12 ; \mathrm{p}<0.02)$ were significantly higher in Group I than in Group II. The Killip score $(\geq \mathrm{II})(34 \%$ vs. $6 \%$; p $<0.05)$, frequency of arrhythmias $(75 \%$ vs. $38 \%$; $\mathrm{p}<0.02)$ and peak $\mathrm{CK}$ value $(3,676 \pm 2,290$ vs. $1,818 \pm 1,153 \mathrm{IU} / \mathrm{L} ; \mathrm{p}<$ 0.005 ) were higher in Group I than in Group II. Four patients in Group I died following admission, while no patient died in Group II (N.S.). Autopsy findings from the 4 Group I patients revealed fresh extensive inferior infarction and healed diffuse subendocardial infarction which could not be predicted from electrocardiograms.

All patients who survived the acute stage performed treadmill exercise testing and 22 patients underwent exercise thallium-201 single photon emission computer tomography (SPECT). On treadmill exercise test, there was no significant difference between the 2 groups in the frequency of angina pectoris and ST-segment depression. On SPECT, the perfusion defect area under $55 \%$ of maximum uptake at the redistribution phase was $45.8 \pm 19.6 \mathrm{~cm}^{2}$ in Group $I(\mathrm{n}=14)$ and $34.7 \pm 21.3 \mathrm{~cm}^{2}$ in Group II ( $\mathrm{n}=8$; N.S.).

In conclusion, precordial ST-segment depression in acute inferior myocardial infarction suggested advanced atherosclerosis in both the infarction-related and nonrelated coronary arteries, indicating a larger infarct size.

From the Department of Cardiology, Koshigaya Hospital, Dokkyo University School of Medicine, Koshigaya, Saitama, Japan.

Address for correspondence: Kan Takayanagi, M.D., Department of Cardiology, Koshigaya Hospital, Dokkyo University School of Medicine, Minami-koshigaya 2-1-50, Koshigaya, Saitama 343, Japan.

Received for publication October 22, 1990.

Accepted September 9, 1991. 


\title{
Key Words:
}

Gensini score Acute myocardial infarction ST-segment depression Coronary angiography Thallium-201 scintigraphy

\begin{abstract}
7 HE mechanism of precordial ST-segment depression in acute inferior 1 myocardial infarction (AMI) has not as yet been clarified despite many clinical studies. ${ }^{1-12)}$ One possibility is reciprocal electrocardiographic changes opposite the area of ST-segment elevation and another possibility is simultaneous myocardial ischemia in the area supplied by the infarctionnonrelated coronary arteries. However, quantitative analysis of coronary artery sclerosis in patients with and without precordial ST-segment depression is scarce. Most reports used simple scoring systems such as single, double or triple vessel disease. ${ }^{2,4), 6)}$ To express the degree of coronary atherosclerosis more quantitatively, we applied the Gensini scoring system to the coronary artery stenosis in 2 groups of patients with inferior AMI with $(\geq 1$ $\mathrm{mm}$ in $\left.\mathrm{V}_{\mathrm{g}}-\mathrm{V}_{6}\right)$ and without $(<1 \mathrm{~mm})$ precordial ST-segment depression. ${ }^{13}$
\end{abstract}

\section{Methods}

Patients: From 1985 to 1990, 44 consecutive patients admitted to our hospital with a first transmural inferior AMI were included in this study when they satisfied the following criteria: (1) history of typical chest pain, electrocardiographic (ECG) changes (ST-segment elevation followed by new $Q$ waves of more than $30 \mathrm{msec}$ width in at least two of the leads II, III, $\mathrm{aV}_{\mathrm{F}}$ ), rise of serum creatine phosphokinase $(\mathrm{CK})$ and a $\mathrm{CK}-\mathrm{MB}$ isoenzyme level higher than twice the upper limit of normal; (2) no history or ECG evidence of prior $\mathrm{MI}$; (3) absence of left or right bundle branch block; (4) coronary angiography performed within 6 weeks of the onset; (5) no history and findings of valvular heart disease, congenital heart disease and cardiomyopathy. Forty-two patients met these criteria. In an additional 2 patients who died during admission and in whom coronary angiography could not be performed, coronary pathological findings at autopsy were used for the analysis.

Electrocardiography: In all patients, the first standard 12-lead ECGs were recorded within 6 hours after the onset of chest pain. ECGs were also recorded every 4 hours on the first day and then once daily during the first week and at least every 5 days until the patients' discharge. Precordial ST-segment depression was defined as more than $1 \mathrm{~mm}$ horizontal or downward depression at $0.08 \mathrm{sec}$ from the $J$ point of the QRS complex in more than two anterior leads from $\mathrm{V}_{2}$ to $\mathrm{V}_{6}$. After admission, the ECG was continuously monitored with an automatic arrhythmia analyzer (Nihon 
Kohden, OCC-7101), which also recorded consecutive heart beats at a paper speed of $0.3 \mathrm{~cm} / \mathrm{sec}$ during the acute stage of infarction. Holter ECG was performed if sinus bradycardia, second degree or advanced atrioventricular block was observed. According to the presence or absence of significant precordial ST-segment depression on admission as defined above, patients were divided into 2 groups; Group I with ST-segment depression and Group II without ST-segment depression.

Presence or absencc of arrhythmias that necded immediate treatment was checked in each patient. The following arrhythmias were included: Ventricular arrhythmias; ventricular premature beats ( $230 /$ hour), ventricular tachycardia (at least a triplet of ventricular premature beats), and ventricular fibrillation. Atrial arrhythmias; paroxysmal supraventricular tachycardia and atrial fibrillation. Atrioventricular block (more than second degree) and sinus arrest.

Coronary angiography: Coronary angiography was performed by Judkins' technique following left ventriculogram in the right anterior oblique view. Coronary artery stenosis was assessed according to the Gensini scoring system on the coronary angiogram in each patient as originally described. ${ }^{13}$ ) In the autopsied heart, the epicardial coronary arteries were cut in $5 \mathrm{~mm}$ intervals and the same scoring system was applied.

Exercise electrocardiogram and thallium-201 myocardial tomography: Patients who had survived the acute stage of myocardial infarction were studied with treadmill exercise testing under the modified Bruce protocol before their hospital discharge. Within a week, thallium-201 single photon emission computer tomography (SPECT) was performed in 22 patients with bicycle ergometry from 25 watts at an incremental work load of 25 watts every $3 \mathrm{~min}$. The perfusion defect at the redistribution phase was automatically calculated as the area below $55 \%$ of the maximum uptake with the modified system of Nakajima et al.14),15\} The end points of these exercise tests were angina pectoris, dyspnea, ST-segment depression, frequent ventricular arrhythmias, leg fatigue or hypotension.

Statistical analysis: Data were expressed as mean \pm 1 standard deviation (SD). The $\chi^{2}$ test was used for differences in event frequency between the 2 groups. Unpaired Student t-tests were performed for differences between the 2 groups. A value of $p<0.05$ was considered statistically significant. 


\section{Results}

ST-segment subgroups and clinical characteristics (Table I): Of the 44 patients, 28 had significant precordial ST-segment depression on admission (Group I) while 16 had no significant ST-segment depression (Group II). The clinical characteristics of the 2 groups are presented in Table I. Killip class $(p<0.05)$, frequency of arrhythmias $(p<0.02)$ and peak CK value $(p<0.005)$ were significantly higher in Group I than in Group II. Details of the arrhythmias are documented in the Table under the title of ventricular arrhythmias, supraventricular arrhythmias, atrioventricular block and sinus arrest. Further details are shown in parentheses under each title. Three Group I patients had ventricular fibrillation, and all could be defibrillated. Temporal pacing was performed in only one Group I patient

Table I. Characteristics of the 2 Groups

\begin{tabular}{|c|c|c|c|}
\hline & Group I $(n=28)$ & Group II $(n=16)$ & p Value \\
\hline Clinical features & $($ mean $\pm S D)$ & $($ mean $\pm S D)$ & \\
\hline Age $(y r)$ & $58.9 \pm 9.5$ & $56.2 \pm 10.2$ & N.S. \\
\hline Male/Female & $22 / 6$ & $13 / 1$ & N.S. \\
\hline Killip class $\geq \mathrm{II}$ & 10 & 1 & $\mathrm{p}<0.05$ \\
\hline Arrhythmias & 21 & 6 & $\mathrm{p}<0,02$ \\
\hline Ventricular & 14 & 4 & N.S. \\
\hline arrhythmias* (Vf/VT/VPBs) & $(3 / 2 / 11)$ & $(0 / 2 / 2)$ & \\
\hline Supraventricular & 4 & 0 & N.S. \\
\hline arrhythmias** (Af/PSVT) & $(3 / 1)$ & $(0 / 0)$ & \\
\hline AVB & 4 & 0 & N.S. \\
\hline (second/third degree) & $(0 / 4)$ & $(1 / 1)$ & \\
\hline Sinus arrest & 1 & 0 & N.S. \\
\hline Peak CK (IU/L) & $3,676 \pm 2,290$ & $1,818 \pm 1,153$ & $\mathrm{p}<0.005$ \\
\hline Deaths & 4 & 0 & N.S. \\
\hline \multicolumn{4}{|l|}{ Angiographic findings } \\
\hline \multicolumn{4}{|l|}{ Infarct-related vessel } \\
\hline Right coronary artery $(n=41)$ & 25 & 16 & N.S. \\
\hline Left circumflex artery $\quad(n=3)$ & 3 & 0 & N.S. \\
\hline Single vessel disease $\quad(n=10)$ & 3 & 7 & $\mathrm{p}<0.02$ \\
\hline Multi vessel disease & 25 & 9 & $p<0.02$ \\
\hline Collateral vessels & 11 & 6 & N.S. \\
\hline Significant LAD stenosis & 22 & 3 & $\mathrm{p}<0.001$ \\
\hline
\end{tabular}

Abbrcviations : $\mathrm{Af}=$ atrial fibrillation**; $\mathrm{AVB}=$ atrioventricular block; $\mathrm{CK}=$ creatine phosphokinase ; $L A D=$ left anterior descending coronary artery; N.S. = no significant difference; PSVT = paroxysmal supraventricular tachycardia**; $\mathrm{SD}=$ standard deviation; $\mathrm{Vf}=$ ventricular fibrillation*; VPBs= ventricular premature beats*; VT = ventricular tachycardia*. 
who showed sinus arrest. There were no arrhythmic deaths in either group. Four Group I patients died during the acute phase and all were autopsied (Table II), while no Group II patients died (N.S.).

Coronary angiographic findings (Table I): In Group I, the infarct-related vessel was observed to be the right coronary artery (RCA) in 25 patients and the left circumflex artery (LCX) in 3 patients. In Group II, the infarct-related vessel was the RCA in all 16 patients. Single vessel disease was seen in 3 patients in Group I and in 7 in Group II $(p<0.02)$, whereas multivessel involvement was observed in 25 patients in Group I and 9 in Group II ( $89 \%$ vs. $56 \%$; p < 0.02$)$. Significant $(\geq 70 \%)$ concomitant left anterior descending artery (LAD) disease was present in 22 patients in Group I and in 3 patients in Group II $(79 \%$ vs. $19 \% ; \mathrm{p}<0.001)$. The Gensini score of coronary arteries for each patient is illustrated in Fig. 1. It was significantly higher in Group I than in Group II (56.3 \pm 29.3 vs. $27.5 \pm 17.5 ; \mathrm{p}<0.001)$. The scores of the autopsied patients are indicated by crosses. The partial scores of the infarction-related artery $(29.1 \pm 16.0$ vs. $16.5 \pm 10.8 ; \mathrm{p}<0.01)$ and of the infarction-nonrelated artery $(27.1 \pm 23.9$ vs. $11.0 \pm 12.2 ; \mathrm{p}<0.02$ ) were also significantly higher in Group I than in Group II.

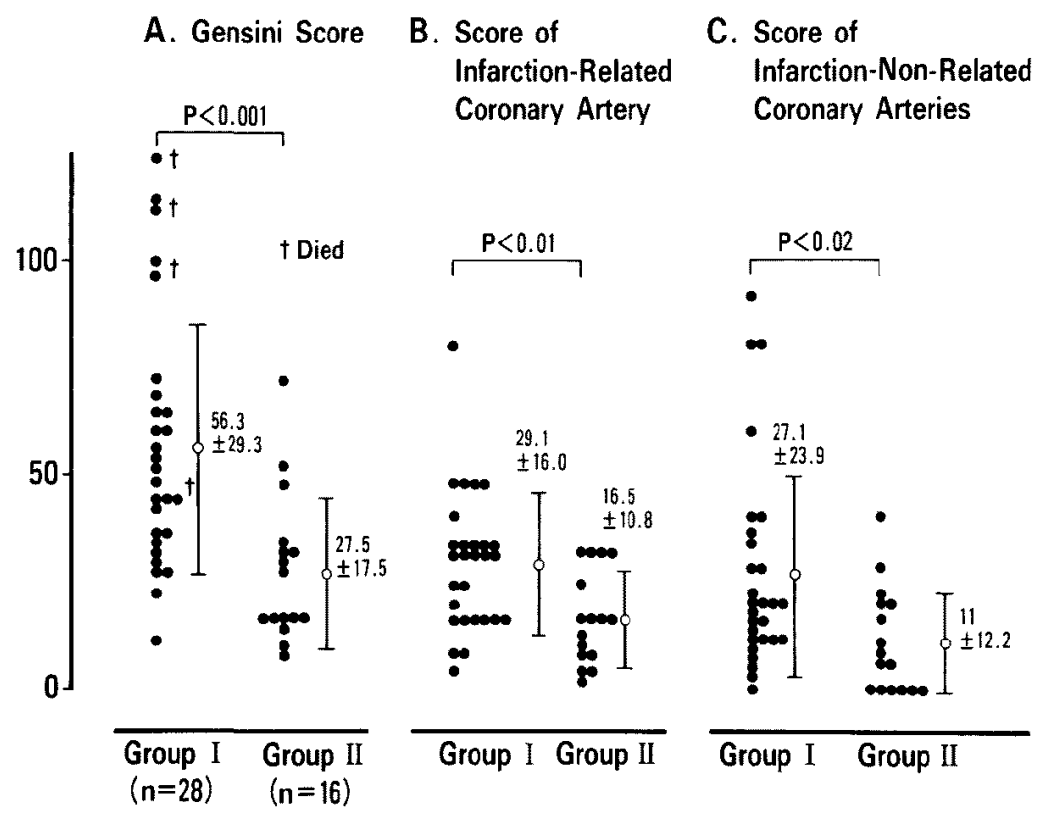

Fig. 1. Left: Gensini score of the coronary artery in Group I and Group II including 4 Group I patients who died in the acute stage. Middle: Part score of the infarction-related coronary artery. Right: Part score of the infarction-nonrelated coronary artery. 


\section{Duration of ST-segment deviation in lead $\mathrm{aV}_{\mathrm{F}}$ and in precordial}

leads: In each patient, the duration of ST-segment elevation in lead $\mathrm{aV}_{\mathrm{F}}$ and the ST-segment depression in the precordial leads was recorded. The ST-segment elevation in lead aV $V_{F}$ lasted more than 24 hours in 14 Group I patients and in 4 Group II patients ( $50 \%$ vs. $25 \%$; p < 0.05$)$. In Group I, ST-segment depression persisted for more than 24 hours in lead $\mathrm{V}_{\mathrm{s}}$ in 9 patients $(32 \%)$ and in lead $V_{5}$ in 9 patients $(32 \%)$. In Group II, none showed ST-segment depression for more than 24 hours. In 14 Group I patients, at least one of the ST-segment deviations (ST-segment depression in lead $\mathrm{V}_{3}$ or $\mathrm{V}_{5}$, or elevation in $\mathrm{a} \mathrm{V}_{\mathrm{F}}$ ) persisted for more than 24 hours. It is noteworthy that 9 of these 14 patients, who showed ST-segment deviations in all three leads for more than 24 hours, had multivessel coronary involvement, including the LAD and marked stenosis $(>90 \%)$ in the infarction-related right coronary artery. In these patients, subsequent arrhythmias were observed: ventricular tachycardia and fibrillation $(\mathrm{n}=2)$, paroxysmal atrial fibrillation $(\mathrm{n}=2)$, complete atrioventricular block $(\mathrm{n}=4)$, sinus arrest with atrioventricular junctional rhythm $(\mathrm{n}=1)$. Three of these 9 patients, who were 70 years or older, died of extensive myocardial infarction as shown at autopsy.

Autopsy findings of Group I patients: Four Group I patients died of congestive heart failure and all were autopsied. Their pathological findings are listed in Table II. All had large and fresh inferior myocardial infarction with healed subendocardial infarction. Figure 2 depicts the loca-

Table II. Characteristics of Autopsied Cases

\begin{tabular}{|c|c|c|c|c|c|c|c|c|}
\hline No. Case & $\begin{array}{l}\text { Age } \\
\text { Se }\end{array}$ & $=8$ & $\begin{array}{l}\text { Duration } \\
\text { /Peak CK } \\
\text { (IU/L) }\end{array}$ & Arrhythmias & $\begin{array}{l}\text { Killip } \\
\text { class }\end{array}$ & $\begin{array}{l}\text { Cause of } \\
\text { death }\end{array}$ & $\begin{array}{l}\text { Heart } \\
\text { weight }\end{array}$ & $\begin{array}{l}\text { Coronary } \\
\text { lesion }\end{array}$ \\
\hline 1. W. E. & & $\mathrm{F}$ & $\begin{array}{l}4 \text { days } \\
/ 1197\end{array}$ & VPBs & III & CHF & $340 \mathrm{~g}$ & $\begin{array}{lrr}\text { RCA } & \# 1 & 100 \% \\
\text { LMT } & \# 5 & 75 \% \\
\text { LAD } & \# 6 & 90 \% \\
\text { LAD } & \# 8 & 90 \% \\
\text { LCX } & \# 11 & 99 \%\end{array}$ \\
\hline 2. K. F. & 66 & $\mathbf{M}$ & $\begin{array}{l}34 \text { days } \\
/ 2225\end{array}$ & $A f, V T, V f$ & III & $\begin{array}{c}\text { CHF, } \\
\text { Pneumonia }\end{array}$ & $440 \mathrm{~g}$ & 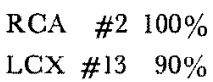 \\
\hline 3. N. H. & 70 & $\mathbf{F}$ & $\begin{array}{l}57 \text { days } \\
/ 2010\end{array}$ & $\begin{array}{l}\text { PSVT, } \\
\mathrm{III}^{\circ} \mathrm{AVB} \\
\mathrm{VT}^{\mathrm{V}}, \mathrm{Vf}\end{array}$ & IV & $\mathrm{CHF}$ & $380 \mathrm{~g}$ & $\begin{array}{lrr}\mathrm{RCA} & \# 1 & 100 \% \\
\mathrm{LAD} & \# 6 & 100 \% \\
\mathrm{LCX} & \# 13 & 90 \%\end{array}$ \\
\hline 4. S. S. & & $\mathbf{M}$ & $\begin{array}{l}17 \text { days } \\
/ 6830\end{array}$ & $\begin{array}{l}\text { Af, } \\
\text { II }^{\circ} \mathrm{AVB}\end{array}$ & III & $\mathrm{CHF}$ & $460 \mathrm{~g}$ & 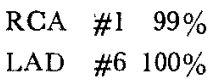 \\
\hline
\end{tabular}

Abbreviations: Af, AVB, CK, LAD, PSVT, Vf, VPBs, VT same as in Table I. CHF= congestive heart failure; $\mathrm{F}=$ female ; $\mathrm{LCX}=$ left circumflex coronary artery; $\mathrm{M}=$ male; $\mathrm{RCA}=$ right coronary artery. 
No. 1

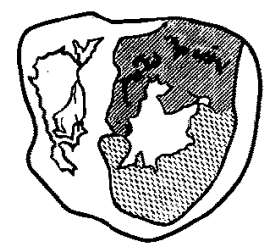

No. 2

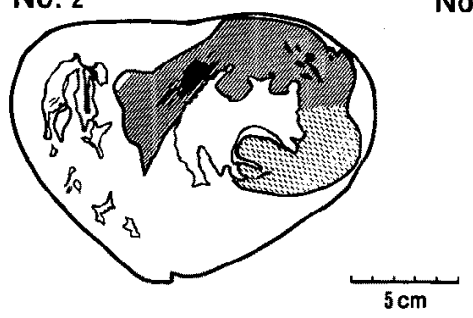

No. 3

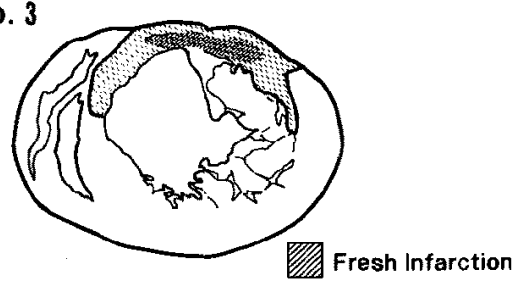

No. 4



Fig. 2, Schematic representation of the transverse section of the heart of 4 patients indicating the location of the fresh transmural infarction (shaded areas) and healed subendocardial infarctions (hatched areas). See Table II for the details of each patient.

tion of the fresh transmural infarction (shaded areas) and healed subendocardial infarction (hatched areas) in the transverse section of the hearts from these 4 patients. Those 4 patients had advanced coronary artery sclerosis in the RCA. The presence of healed subendocardial infarctions could not be diagnosed from the ECG or past histories.

The autopsy and coronary angiographic findings of a Group I 71-yearold woman are illustrated. Six hours after the onset of chest pain, EGG showed $1 \mathrm{~mm}$ ST-segment elevation in lead $\mathrm{aV}_{\mathrm{F}}$ and $3 \mathrm{~mm}$ depression in lead $\mathrm{V}_{3}$. Left coronary angiogram revealed a $95 \%$ stenosis in the left main coronary artery and a $99 \%$ stenosis in segment 11 of the LCX (Fig. 3-A). There was a complete occlusion in segment 2 of the RCA. Intra-coronary administration of 960,000 units of urokinase reperfused the occluded lesion to $99 \%$ stenosis with delayed filling of the distal portion (Fig. 3-B). Serum $\mathrm{CK}$ increased to $1,197 \mathrm{IU} / \mathrm{L}$ and the ST-segment depression in lead $\mathrm{V}_{\mathbf{3}}$ persisted. On her fourth hospital day, she died of heart failure. Autopsy revealed a fresh inferior myocardial infarction including the lateral wall and part of the septum (Fig. 2: Case 1). Healed subendocardial infarction surrounding the fresh infarction, marked stenosis of the LAD and the LCX, and complete obstruction of the RCA were observed.

Exercise testing and thallium-201 myocardial tomography in the chronic stage: In the 24 Group I patients who had survived the acute stage and in all 16 Group II patients, exercise testing was performed by the 




Fig. 3. Coronary angiography of Case 1 in Fig. 2. (A) Left coronary arteries. There was a $95 \%$ stenosis in the left main coronary artery (indicated by 2 closed triangles), a 90\% stenosis in segment 8 of the left anterior descending coronary artery and a $99 \%$ stenosis in segment 11 of the left circumflex coronary artery (closed arrow). (B) Right coronary artery after reperfusion. There was a $99 \%$ stenosis in segment 2 of the right coronary artery with delayed filling of the distal portion (open arrow).

modified Bruce protocol before their hospital discharge. There were no significant differences in the exercise duration, maximum, heart rate achieved and pressure-rate-product between the 2 groups (Table III). Eight patients in Group I and 4 patients in Group II showed a significant ST-segment depression (N.S.). Three Group I patients and 1 Group II patient with STsegment depression on exercise also had typical anginal pain. The Gensini score of these patients with exercise-induced ST-segment depression was 
Table III. Results of Exercise Testing

\begin{tabular}{l|c|c|c}
\hline & Group I $(\mathrm{n}=24)$ & Group II $(\mathrm{n}=16)$ & $\mathrm{p}$ Value \\
\hline Duration (seconds) & $423 \pm 124$ & $484 \pm 139$ & N.S. \\
Maximum heart rate (b.p.m.) & $135 \pm 11$ & $128 \pm 26$ & N.S. \\
Pressure rate product & $22,060 \pm 3,790$ & $20,990 \pm 6,370$ & N.S. \\
Hypotension & 1 & 1 & N.S. \\
ST-segment depression & 8 & 4 & N.S. \\
Angina pectoris & 3 & 1 & N.S. \\
\hline
\end{tabular}

$67 \pm 25$ in Group I and $28 \pm 16$ in Group II $(\mathrm{p}<0.02)$.

From 1988, exercise thallium-201 scintigraphy was performed in 14 Group I patients and 8 Group II patients. After exercise, no obvious perfusion defect in the anterior area was evidenced in either group. The perfusion defect in the inferior area at the redistribution phase was $45.8 \pm 19.6$ $\mathrm{cm}^{2}$ in Group I and $34.7 \pm 21.7 \mathrm{~cm}^{2}$ in Group II (N.S.).

Typical exercise thallium-201 scintigraphy with ECG findings in a Group I 55-year-old male with diabetes mellitus is illustrated in Figs. 4 and 5. After $2.5 \mathrm{~min}$ of bicycle ergometry, he complained of severe chest pain and demonstrated a marked ST-segment depression (Fig. 4: middle) and had to discontinue the test. The scintigram showed a perfusion defect in the inferior area and a slightly reversible defect in the septum (Fig. 5). He had severe triple vessel disease. His Gensini score was 100 (infarction-related coronary artery: 40 and infarction-nonrelated coronary artery: 60). Five months after discharge, he had another episode of severe chest pain with a $15 \mathrm{~mm}$ ST-segment depression in the same leads (Fig. 4: right) and his serum CK increased to $800 \mathrm{IU} / \mathrm{L}$. He was hospitalized again and aortocoronary bypass surgery was performed.

Representative exercise thallium-201 SPECTs of Group I and Group II patients are illustrated on a modified Bull's eye expression developed on a single plane (Fig. 6: A; Case 15; peak $\mathrm{CK}=8,080$ and B; Case 37; peak CK =495). Perfusion defects in the inferior area, defined as less than $55 \%$ of the maximum uptake, are indicated with green areas surrounded by white lines.

\section{Discussion}

The clinical significance of precordial ST-segment depression in acute inferior infarction has been debated from various viewpoints because such findings could be instantly obtained from admission ECGs. In some reports, patients with precordial ST-segment depression had significant LAD 

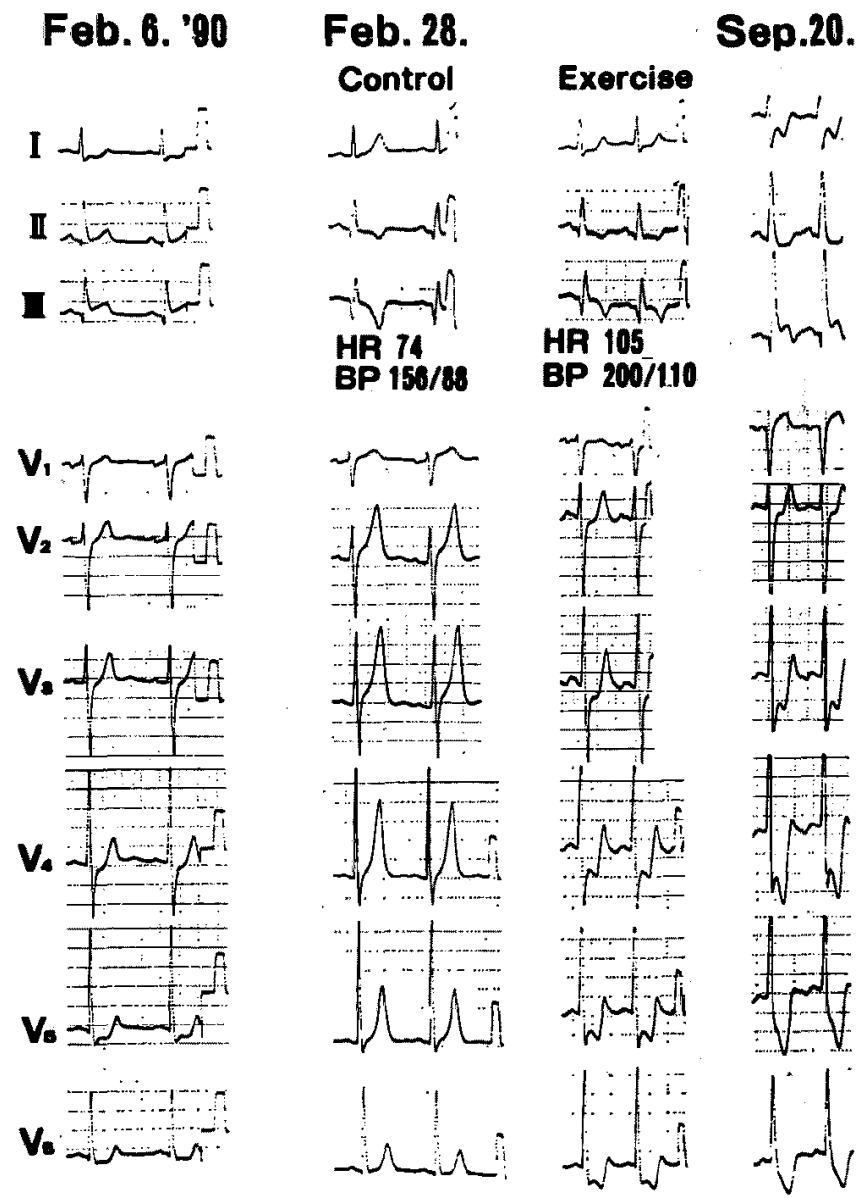

Fig. 4. ECG on admission (February 6) and exercise ECG (February 28) during bicycle ergometry in a 55-year-old Group I patient. He had a reattack with marked precordial ST-segment depression (September 20).

involvement. ${ }^{4-6)}$ In other reports, LAD involvement was not evidenced. ${ }^{\text {2),8) }}$ In our study, we could quantitatively show that the Gensini score was higher in Group I patients than in Group II. As the Gensini score is the sum of the infarction-related vessel and the infarction-nonrelated vessel, we analyzed the details of this score. The score of the infarction-related vessel was significantly higher in patients with precordial ST-segment depression than in those without it. This might be the reason for the larger infarctions in Group I. Furthermore, the score of the infarction-nonrelated vessel was also higher in Group I than in Group II. The higher score of the infarction-nonrelated vessel indicated more severe left coronary artery sclerosis. Whether the advanced left coronary artery sclerosis could directly contribute to the pre- 
Early Image

Delayed Image

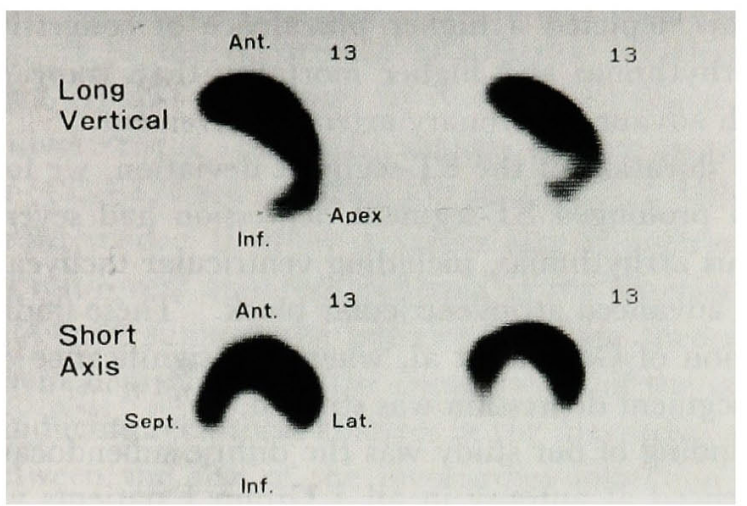

Fig. 5. Exercise thallium-201 scintigram in the patient shown in Fig. 4. Left: Early image. Right: Delayed image. Perfusion defect in the inferior area is evidenced.

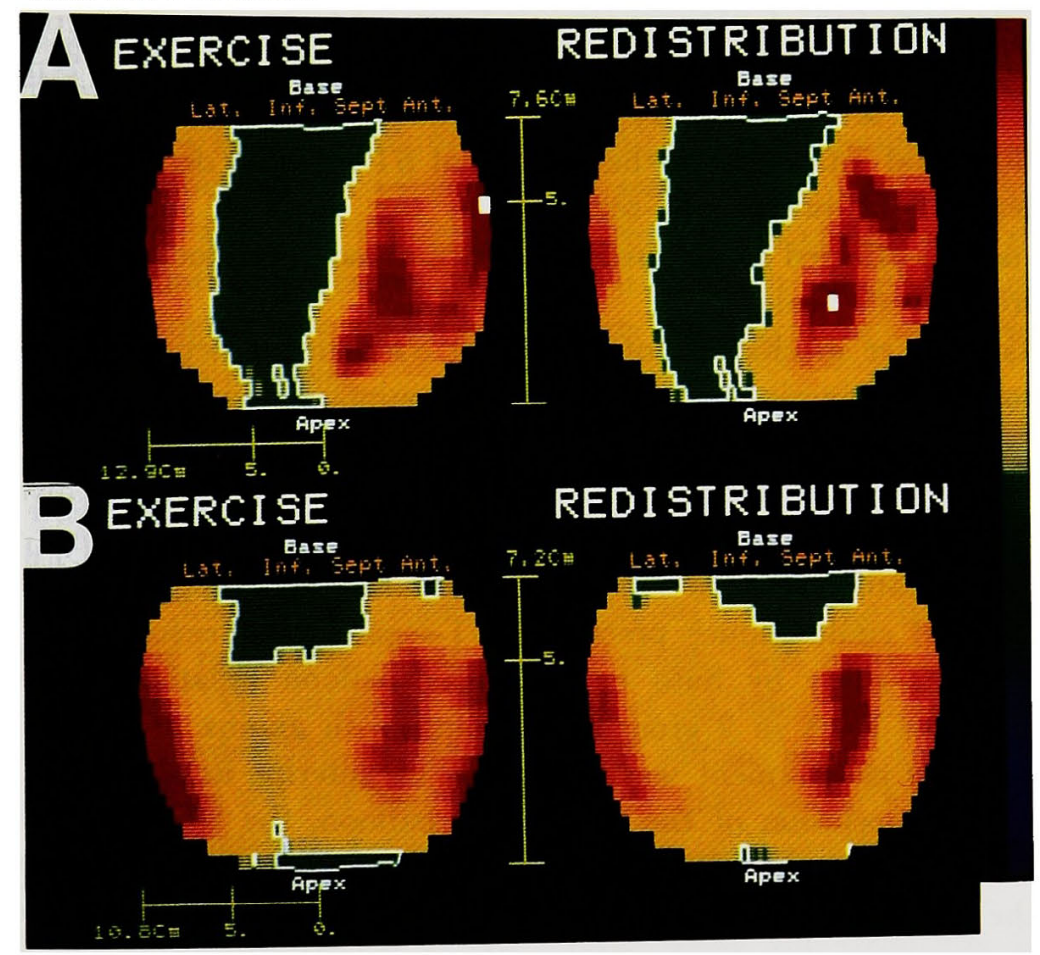

Fig. 6. Exercise thallium-201 scintigram in Group I (A) and Group II (B) patients on modified Bull's eye expression. (A) Case 15: 50-year-old man. Maximum CK 8,080 IU/L. LV surface area: $173.0 \mathrm{~cm}^{2}$, Exercise; uptake $<$ $65 \%$ area: $60.4 \mathrm{~cm}^{2}$, Redistribution; uptake $<55 \%$ area: $62.4 \mathrm{~cm}^{2}$. (B) Case 33: 56-year-old man. Maximum CK $495 \mathrm{IU} / \mathrm{L}$. LV surface area: $136.6 \mathrm{~cm}^{2}$, Exercise; uptake $<65 \%$ area: $18.6 \mathrm{~cm}^{2}$, Redistribution; uptake $<55 \%$ area: $11.5 \mathrm{~cm}^{2}$. Vertical color bar on the right shows calibration of the uptake. Red area indicates $100 \%$ uptake and blue area indicates $0 \%$ uptake. 
cordial ST-segment depression remains unsettled. The clinical profiles of Group I patients depicted a higher prevalence of congestive heart failure, more severe arrhythmias and higher mortality than those of Group II, all compatible with advanced coronary artery involvement.

As for the duration of the ST-segment deviation, we found that Group I patients with prolonged ST-segment depression had severe LAD involvement and serious arrhythmias, including ventricular tachycardia, ventricular fibrillation and advanced atrioventricular block. These findings were similar to the observation of Gelman et al, where the significance of the prolonged precordial ST-segment depression was stressed. $\left.{ }^{6}\right)$

Another finding of our study was the diffuse subendocardial myocardial infarction evidenced at autopsy in all 4 Group I patients who died of congestive heart failure. Three of them had severe LAD or left main coronary artery involvement as shown on the coronary angiogram (Fig. 3). The severe stenosis of the LAD was seen in 1 patient to be completely obstructed at autopsy. Those subendocardial infarctions as shown in Fig. 2 might be the results of severe coronary artery sclerosis. Contribution of the acute subendocardial infarction to the precordial ST-segment depression has been considered. ${ }^{16)}$ However, ST-segments at the onset of inferior infarction could not be affected in our patients, since those subendocardial infarctions had already been healed.

As another mechanism of precordial ST-segment depression, the compensatory hyperkinetic wall motion of the noninfarcted area during the acute phase of myocardial infarction has been suspected. ${ }^{17)}$ In clinical cases, coronary flow to the noninfarcted anterior area during an acute myocardial infarction could be reduced by a critical stenosis of the left coronary artery. The compensatory hyperactivity in the anterior area might aggravate the ischemia and could induce precordial ST-segment depression. An electrocardiographic study by Sato et al during balloon inflation for coronary angioplasty of RCA in 2 groups of patients with angina pectoris with and without LAD involvement was suggestive of anterior ischemia. ${ }^{18)}$ After a few minutes' occlusion of the RCA by a balloon, the ST-segment was depressed in both groups without any significant increase of lactate extraction from the great cardiac vein. Therefore, they concluded that the precordial ST-segment depression during RCA occlusion was due to a reciprocal change and not due to ischemia in the anterior wall. Body surface ST-segment potential mapping during acute myocardial infarction also supported the reciprocal theory showing that a large area of marked anterior ST-segment depression was associated with a high rate of complication and lower survival. ${ }^{12}$ 
In our study, exercise ECG testing in the chronic stage could not reveal significant differences in the occurrence of ischemic ST-changes and chest pain between the 2 groups. This may be due to the various patterns of left coronary artery involvement and to the slightly shorter exercise duration in Group I patients ( $423 \pm 124 \mathrm{sec}$ vs. $484 \pm 139 \mathrm{sec}$; N.S.). Although the thallium-201 scintigram tended to show a larger size of inferior infarction in Group I, it could not reveal apparent ischemia in the anterior area. Therefore, we could not fully support the anterior ischemia theory. We suspect that the ST-segment depression was the consequence of the larger infarction size in Group I, inducing reciprocal changes in the precordial area.

Relation between the size of the myocardial infarction and degree of precordial ST-segment depression has to be considered theoretically. In an experimental study using isolated rabbit heart, Mirvis et al recorded the isopotential distribution of the ST-segment deviation after proximal and distal ligation of the anterior descending coronary artery. ${ }^{19)}$ They found that the maximum and minimum were stronger with the proximal ligation as a consequence of a greater amount of injured tissue. Although the precise size of the infarction was not measured, this study revealed the relation between the infarct size and ST-segment depression. Experimental studies analyzing ST-segment depression during right coronary artery ligation are limited. We thought it necessary to estimate the exact size of inferior infarctions in clinical situations.

Recently, Ide et al reported quantification of the extent of myocardial infarction by thallium-201 SPECT. ${ }^{20}$ As far as we know, this is the only study in which the size of the infarction was measured on SPECT and compared with the actual size of the infarction at autopsy. They found that setting the lower limit to 2.5 standard deviations below the mean values, normalized to the maximum count in each profile, was most accurate for the quantification. We estimated the extent of the infarction from the hypoperfusion area under $55 \%$ of the maximum uptake at the redistribution phase. Although we did not have the autopsied cases in our SPECT study, Group I patients tended to have a larger defect area at the redistribution phase suggesting a larger infarction.

There are some limitations in our study. First, the weighting in the Gensini scoring system for the right coronary artery $(x 1)$ is not as high as for the left coronary artery $(\times 2.5-\times 5)$. This might induce a discrepancy between the actual severity of coronary artery stenosis and the obtained scores, especially if the proximal portion of the right coronary artery was occluded. Another limitation is the lack of pathological findings in Group II patients. Although this seemed to be related to the better prognosis in 
Group II than in Group I, a larger number of patients without ST-segment depression has to be followed in order to make a valid comparison. Thirdly, quantification of the infarction size from the defect area in our SPECT study is not yet established. Therefore, further improvement including comparison with autopsy findings is necessary.

In conclusion, application of the Gensini score quantitatively revealed that patients with precordial ST-segment depression had more severe coronary artery involvement in both the infarction-related and nonrelated vessels than patients without depression. Therefore, ST-segment depression could be due, at least in part, to a larger size of infarction.

\section{REFERENGES}

1. Shah PK, Pichler M, Maddahi J, Peter T, Singh BN, Swan HJC: Noninvasive identification of a high risk subset of patients with acute inferior myocardial infarction. Am J Cardiol 46: 915,1980

2. Salcedo JR, Baird MG, Chambers RJ, Beanlands DS: Significance of reciprocal ST-segment depression in anterior precordial leads in acute inferior myocardial infarction: Concomitant left anterior descending coronary artery disease? Am J Cardiol 48: 1003, 1981

3. Goldberg HL, Borer JS, Jacobstein JG, Kluger J, Scheidt SS, Alonso DR: Anterior ST-segment depression in acute inferior myocardial infarction: Indicator of posterior infarction. Am J Cardiol 48: 1009, 1981

4. Gibson RS, Crampton RS, Watson DD, Taylor GJ, Carabello BA, Holt ND, Beller GA: Precordial ST-segment depression during acute inferior infarction: Clinical, scintigraphic and angiographic correlations. Circulation 66: 732, 1982

5. Croft CH, Woodward W, Nicod P, Corbett JR, Lewis SE, Willerson JT, Rude RE: Clinical implications of anterior ST-segment depression in patients with acute inferior myocardial infarction. Am J Cardiol 50: 428, 1982

6. Gelman JS, Saltups A: Precordial ST-segment depression in patients with inferior myocardial infarction: Clinical implication. Br Heart J 48: 560, 1982

7. Ferguson DW, Pandian N, Kioschos $\ M$, Marcus ML, White CW: Angiographic evidence that reciprocal ST-segment depression during acute myocardial infarction does not indicate remote ischemia: Analysis of 23 patients. Am J Cardiol 53: 55, 1984

8. Boden WE, Bough EW, Korr KS, Russo J, Gandsman EJ, Shulman RS: Inferoseptal myocardial infarction: Another cause of precordial ST-segment depression in transmural inferior wall myocardial infarction? Am J Cardiol 54: 1216, 1984

9. Hlatky MA, Califf RM, Lee KL, Pryor DB, Wagner GS, Rosati RA: Prognostic significance of precordial ST-scgment depression during inferior acute myocardial infarction. Am J Cardiol 55: 325, 1985

10. Lew AS, Maddahi J, Shah PK, Weiss AT, Peter T, Berman DS, Ganz W: Factors that determine the direction and magnitude of precordial ST-segment deviations during inferior wall acute myocardial infarction. Am J Cardiol 55: 883, 1985

11. Ruddy T, Yasuda T, Gold HK, Leinbach RC, Newell JB, McKusick KA, Boucher CA, Strauss HW: Anterior ST segment depression in acute inferior myocardial infarction as a marker of greater inferior, apical, and posterolateral damage. Am Heart J 112: 1210, 1986

12. Bell AJ, Loughhead MG, Walker SJ, Kilpatrick D: Prognostic significance of ST potentials determined by body surface mapping in inferior wall acute myocardial infarction. Am J Cardiol 64: 319, 1989 
13. Gensini GG: Coronary Arteriography, Futura Publishing Co, New York, p 271, 1975

14. Nakajima K, Bunko $H$, Taniguchi $M$, Taki J, Nanbu I, Shire $Y$, Tonami N, Hisada K, Sugimoto N, Ikeda $T$ : Evaluation of coronary artery disease by functional mapping of Thallium201 myocardial perfusion. Nuclear Medicine 23: 473, 1986 (in Japanese with English abstract)

15. Garcia EV, Van Train K, Maddahi J, Prigent F, Friedman J, Areeda J, Waxman A, Berman DS: Quantification of rotational thallium-201 myocardial tomography. J Nucl Med 26: 17, 1985

16. Raunio H, Rissanen V, Helin M, Rehnberg S, Romppanen $\mathrm{T}$, Janatuinen E: Early pronounced ST segment depression with marked J point decline heralding acute lethal clinical myocardial infarction: Necropsy-electrocardiographic correlative study. Am Heart J 103: 32,1982

17. Noma S, Askenase AD, Weintraub WS, Klein LW, Agarwal JB, Helfant RH: Augmentation of contraction in remote nonischemic zone during acute ischemia. Am J Physiol 255: H301, 1988

18. Sato H, Kodama K, Masuyama $T$, Nanto $S$, Hori M, Kitabatake A, Inoue M, Kamada T: Right coronary artery occlusion: Its role in the mechanism of precordial ST segment depression. J Am Coll Cardiol 14: 297, 1989

19. Mirvis DM, Keller FW, Ideker RE, Zettergren DG, Dowdie RF : Equivalent generator properties of acute ischemic lesions in the isolated rabbit heart. Circ Res 42: 676, 1978

20. Ide H, Yamada H, Ohkawa S, Sugiura M, Harumi K: Quantification of the extent of myocardial infarction by thallium-201 single photon emission computed tomography: Comparison with postmortem findings. J Cardiol 20: 1, 1990 (in Japancse with English abstract) 